\title{
Évelyne Trouillot, Absences sans frontières
}

\section{Emanuela Cacchioli}

\section{(2) OpenEdition}

\section{Journals}

\section{Edizione digitale}

URL: http://journals.openedition.org/studifrancesi/2320

DOI: $10.4000 /$ studifrancesi.2320

ISSN: 2421-5856

\section{Editore}

Rosenberg \& Sellier

\section{Edizione cartacea}

Data di pubblicazione: 1 aprile 2014

Paginazione: 198-199

ISSN: 0039-2944

\section{Notizia bibliografica digitale}

Emanuela Cacchioli, «Évelyne Trouillot, Absences sans frontières », Studi Francesi [Online], 172 (LVIII | I) | 2014, online dal 01 avril 2014, consultato il 18 septembre 2020. URL : http://journals.openedition.org/ studifrancesi/2320 ; DOI : https://doi.org/10.4000/studifrancesi.2320

\section{Questo documento è stato generato automaticamente il 18 settembre 2020.}

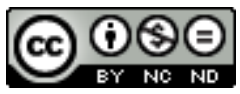

Studi Francesi è distribuita con Licenza Creative Commons Attribuzione - Non commerciale - Non opere derivate 4.0 Internazionale. 


\title{
Évelyne Trouillot, Absences sans frontières
}

\author{
Emanuela Cacchioli
}

\section{NOTIZIA}

ÉVELYNE TROUILLOT, Absences sans frontières, Montpellier, Éditions Chèvre-feuille étoilée, 2013, pp. 256.

1 L'ultimo romanzo di Évelyne Trouillot racconta il rapporto tra un padre e una figlia. Gérard, emigrato haitiano, vive a New York, dove pratica numerosi mestieri per assicurare un presente decoroso e un futuro brillante alla figlia Géraldine che è rimasta nell'isola caraibica. Orfana di madre dall'età di tre anni, la bambina cresce circondata dall'amore della nonna materna e della prozia e diventa una giovane donna di diciassette anni, un po' ribelle, ma molto più matura della sua età. Le numerose attività del padre le garantiscono una certa agiatezza, ma non le impediscono di osservare la realtà sociale della sua isola natale con uno sguardo critico e di collaborare con alcune organizzazioni di volontariato finalizzate ad un miglioramento delle condizioni della popolazione. Rimane, tuttavia, un grande desiderio da realizzare, ossia abbracciare il padre e avere finalmente con lui un contatto fisico. Géraldine è nata quando il genitore era già emigrato negli Stati Uniti e il loro rapporto si è costruito e consolidato per mezzo del telefono e di internet. Da piccola lo ha conosciuto attraverso la voce che fuoriusciva dal ricevitore e ha imparato a comprendere il significato delle pause, dei silenzi e delle accelerazioni che le conversazioni subivano. Con il miglioramento della tecnologia, ha finalmente avuto la possibilità di interagire con il padre, associando al suono le immagini in movimento: i social network e Skype divengono uno strumento di condivisione e un modo per permettere alle loro esistenze di scorrere in parallelo. Per quanto il loro rapporto si consolidi nel tempo, la mancanza di quel contatto fisico che lega un genitore a una figlia rimane il cruccio principale di Géraldine. Il padre, infatti, è un immigrato irregolare e vive di attività sottopagate pur di non incappare in controlli delle autorità che possano costringerlo al rimpatrio. Gérard è un uomo che non accetta 
facili compromessi e preferisce vivere al limite dell'indigenza pur di assicurare un futuro alla figlia. Se Géraldine si trova a condurre un'esistenza agiata in un paese estremamente povero, lo deve a quel padre che vive lontano e che non ha mai potuto abbracciare. Dal canto suo, Gérard innesca una sana competizione con la figlia per ampliare le sue conoscenze. Già diplomato, trascorre il poco tempo libero nelle biblioteche per ricercare verità storiche che spesso vengono taciute, relegate in spazi angusti o dimenticate. L'oblio e i misteri irrisolti sono alcune parole chiave del romanzo: l'esistenza personale e collettiva dei protagonisti è segnata da passaggi oscuri perché volutamente dissimulati. Percepiamo l'ambiguità degli eventi, ma un'apparente coesione ci offre l'illusione della coerenza. Di tanto in tanto, tuttavia, la Storia interviene nelle vite di persone comuni, rompe quell'illusione faticosamente costruita e la verità è dolorosamente ripristinata. Gli incubi, le ossessioni, le falsità lasciano il posto alla sofferenza e a un parziale sollievo che tuttavia non costituisce un risarcimento per nessuno dei protagonisti.

Il romanzo è costruito attraverso brevi capitoli, ognuno dei quali ci offre una prospettiva differente, ma complementare per raccontare un passato doloroso e un presente contrassegnato da catastrofi naturali (su tutte, il terremoto che ha colpito Haiti il 12 gennaio 2010) o volute dall'uomo (la caduta delle Torri Gemelle). I tre punti di vista adottati sono quelli di Gérard, di Géraldine (l'unica a parlare in prima persona) e della nonna Gigi, una donna combattiva ma lacerata interiormente. Una tecnica paragonabile all'arte cinematografica che permette a Évelyne Trouillot di ricostruire le vicende personali e collettive dei personaggi in modo originale, ma anche di affrontare da prospettive nuove temi attuali quali l'omosessualità, l'esigenza della tecnologia moderna e il bisogno di riscoprire antichi riti ancestrali. 